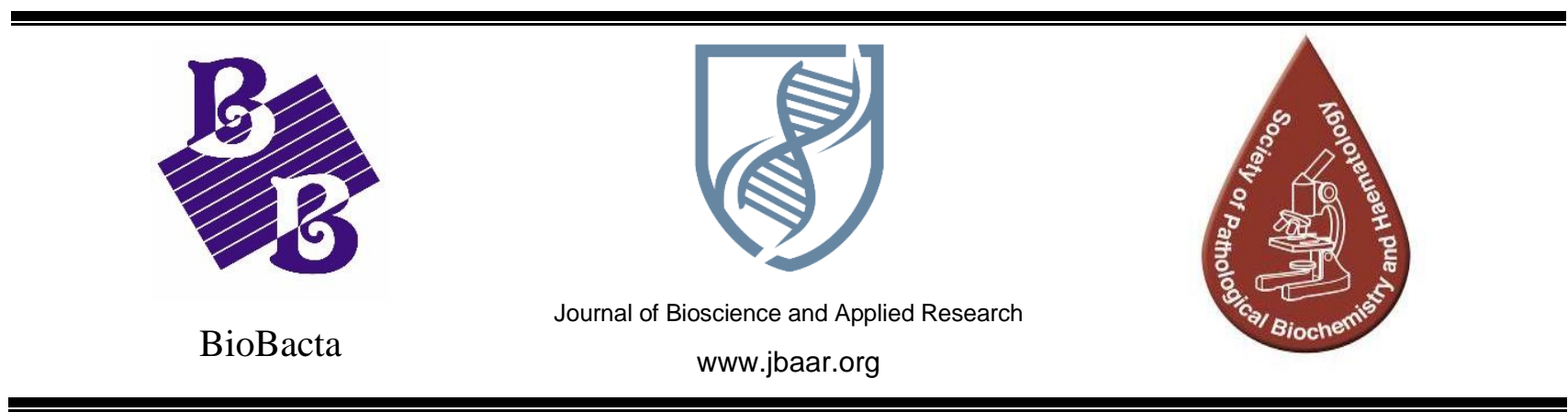

\title{
Breast cancer risk associated with genotype polymorphism of COMT gene in young women
}

\author{
Abbas Ch. Mraissl \\ Pathology /Biology Department, Education College, Missan University, Iraq
}

\section{ABSTRACT}

DOI: 10.21608/jbaar.2018.152798

O- methylation mediated by COMT enzyme is an important mechanism for inactivating Catechole Estrone (CE) which including 2- HE and 4- HE and transform it to 2-ME and 4-ME which act as anti- tumor genesis. This study aimed to investigate the association between the polymorphism in COMT genotype and the breast cancer risk in (40) young patient's women aged between (20-39) years were diagnosed and confirmed with breast carcinoma at AL- Sadder hospital in Missan, and (40) healthy control women aged between (18-39) years in the period between September -2009 to April -2010 Odds ratios(OR) and confidence interval (CI) were calculated in level significant $\mathrm{P}<0.05$. The statistical analysis showed no association between the breast cancer risk in young women and homozygous wild (Met/Met) genotype with an OR of 0.63(95\% CI= $0.248-0.552$ ), also with heterozygous (Val/Met) genotype with an OR of $0.93(95 \% \mathrm{CI}=0.155-0.44$ ), and when a combination $(\mathrm{Met} / \mathrm{Met}+\mathrm{Met} / \mathrm{Val})$ genotype with an $\mathrm{OR}$ of $0.78(95 \% \mathrm{CI}=0.559-0.841)$, compared to homozygous mutant ( $\mathrm{Val} / \mathrm{Val})$ genotype. No significant differences in frequency of low activity alleles between cases and controls, indicating the polymorphism as a single factor may not contribute to breast carcinogenesis in young women.

Abbreviations: COMT, Catechol -O- Methyl Transferase; HE, Hydroxy Estrone; ME, Methoxy Estrone; OR, Odds Ratios; CI, Confidence Interval; Val, Valin; Met, Methionine.

Keywords: $C O M T$ gene, Breast cancer, genotype, polymorphism, breast carcinoma

\section{INTRODUCTION}

Breast cancer is considered the second commonest cause of cancer death and one of the most dreading diseases of women (1). No one has known the exact causes of breast cancer but many risk factors increase a person's chance of developing the disease. Estrogen exposure has been considered to be one of the main risk factors for breast cancer. One characteristic of estrogen is its mitogenic action in hormone-sensitive tissues such as the uterus and breast (2).

Estrogen metabolite produces two catechol estrogens 2-hydroxyestradiol(2- HE) and 4hydroxyestradiol (4- HE) have shown several biological effects, where the 4- hydroxyestradiol 
metabolite binds and activates the estrogen receptor with approximately the same affinity as estradiol, However, the interaction with hormone receptor is markedly reduced for the 2-HE, which therefore may possess a weaker hormonal potency as compared with the parent hormone estradiol. thus, promotes cell proliferation and carcinogenesis (3).

One of the major inactivation pathways of 2- and 4HE is through O-methylation of 2 and 4 - methoxy estradiol by enzyme Catechol - O - Methyl Transferase (COMT), where COMT activity is lightly present in the liver and kidney, and it is also found as significant levels in the brain, uterus in endometrium and the mammary gland (4)

Little is known about other factors implicated in breast carcinogenesis among young women. most of the current risk factors, including women's menarche and menopause, age at the first full-time pregnancy as well as the number of parturition are indicators of cumulative estrogen exposure (5).

Recent studies hypothesized that the polymorphism in the gene coding for enzymes involved in estrogen metabolism may be predisposing to breast cancer.

The present study intended to investigate the association between the low -activity for COMT gene and risk of breast cancer in young women patients and compared with control population consisting of young healthy females.

\section{MATERIAL AND METHODS}

\section{1- Collection of the samples:}

Five $\mathrm{ml}$ of the peripheral blood samples were collected in sterilized tubes with EDTA from forty young female breast cancer patients aged between (20-39) years, and forty healthy females aged between (18-39)as control (blood donor). The breast cancer patients were diagnosed and confirmed with breast carcinoma at AL-Sadder hospital in Missan governorate between (September -2009 to April -
2010). Blood samples were transferred to the laboratory and kept directly in (-20C) until extraction of the genomic DNA.

\section{2- Isolation and Estimation of DNA:}

DNA was isolated by using the modified Sambrook method (6) that was described by ALQurashi (7), where genomic DNA was obtained by congenital Phenol/Chloroform extraction followed by ethanol precipitation and storied at $(-18 \mathrm{C})$. The concentration of isolated DNA was calculated by a spectrophotometric method using U.V-visible scanning spectrophotometer(Fig .1.).

\section{3- Polymerase chain reaction:}

The isolated DNA was assayed by PCR with specific primers (COMT primers) forward 5- $\mathrm{G}$ CCCGCCTGCTGTCACC-3 and reveres 5CTGAGGGGCCTGGTGATAGTG-3. The polymorphism of the COMT gene was studied according to a protocol described by (7)., after that, the products were detected by electrophoresis in $2 \%$ agarose gel, and the COMT gene PCR fragment was $114 \mathrm{bp}$.

PCR products were digested with Hsp 92II restriction enzyme and the digestion product was classified as homozygous wild type (50-64bp), Homozygous mutant type( 50 or 64-114 ), and Heterozygous (50-114,69-114) alleles (Fig .2.).

\section{THE RESULTS}

The frequencies of the COMT genotype among the breast cancer patients and the control population are shown in Tab (1).

Statistical analysis by calculated Odds Ratios $(\mathrm{OR})$ and $\mathrm{P}$ values $(\mathrm{P}<0.05)$ revealed no association between the breast cancer risk and homozygous wild (Met/Met) genotype with an OR of $0.63(95 \% \mathrm{CI}=$ $0.248-0.552$ ), also with heterozygous (Val/Met) genotype with an OR of $0.93(95 \% \mathrm{CI}=0.155-0.44)$ and when a combination (Met/Met + Met/Val) 
genotype with an OR of $0.78(95 \% \mathrm{CI}=0.559-0.841)$,

compared to homozygous mutant (Val/Val)

genotype.

Table (1) show the allele frequencies of COMT genotype for young breast cancer patients and the control population.

\begin{tabular}{|c|c|c|c|c|}
\hline COMT genotypes & $\begin{array}{c}\text { Control (\%) } \\
\text { no:40 }\end{array}$ & $\begin{array}{c}\text { Cases }(\%) \\
\text { no:40 }\end{array}$ & OR & $(95 \% \mathrm{CI}=)$ \\
\hline $\boldsymbol{C O M T} \boldsymbol{V}_{\mathrm{Val} / \mathrm{Val}}$ & 14 (35) & $10(25)$ & 1.0 & \\
\hline $\boldsymbol{C O M} \boldsymbol{T}_{\text {Val } / \mathrm{Met}}$ & $16(40)$ & $18(45)$ & 0.63 & $0.248-0.552$ \\
\hline $\boldsymbol{C O M T}$ Met $/ \mathrm{Met}$ & $10(25)$ & $12(30)$ & 0.93 & $0.155-0.44$ \\
\hline $\begin{array}{l}\boldsymbol{C O M T} \text { Met /Met + } \\
\boldsymbol{C O M T} \text { Met/Val }\end{array}$ & $26(65)$ & 30(75) & 0.78 & $0.617-0.883$ \\
\hline
\end{tabular}




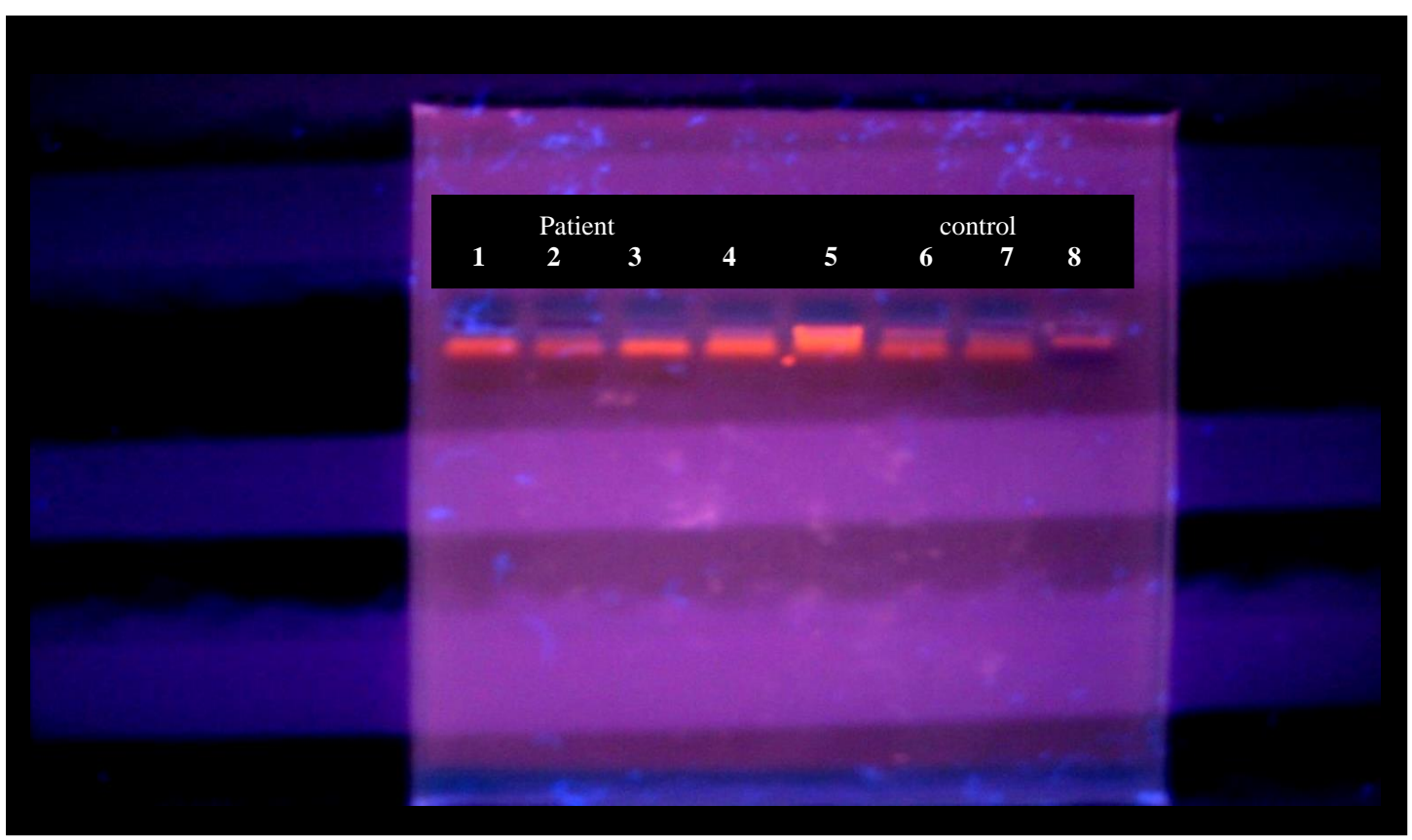

Fig .1. Agarose gel showing the molecular weight of DNA. Lanes $(1,2,3,4$,$) the patient's Lanes (5,6,7,8)$ normal women as control.

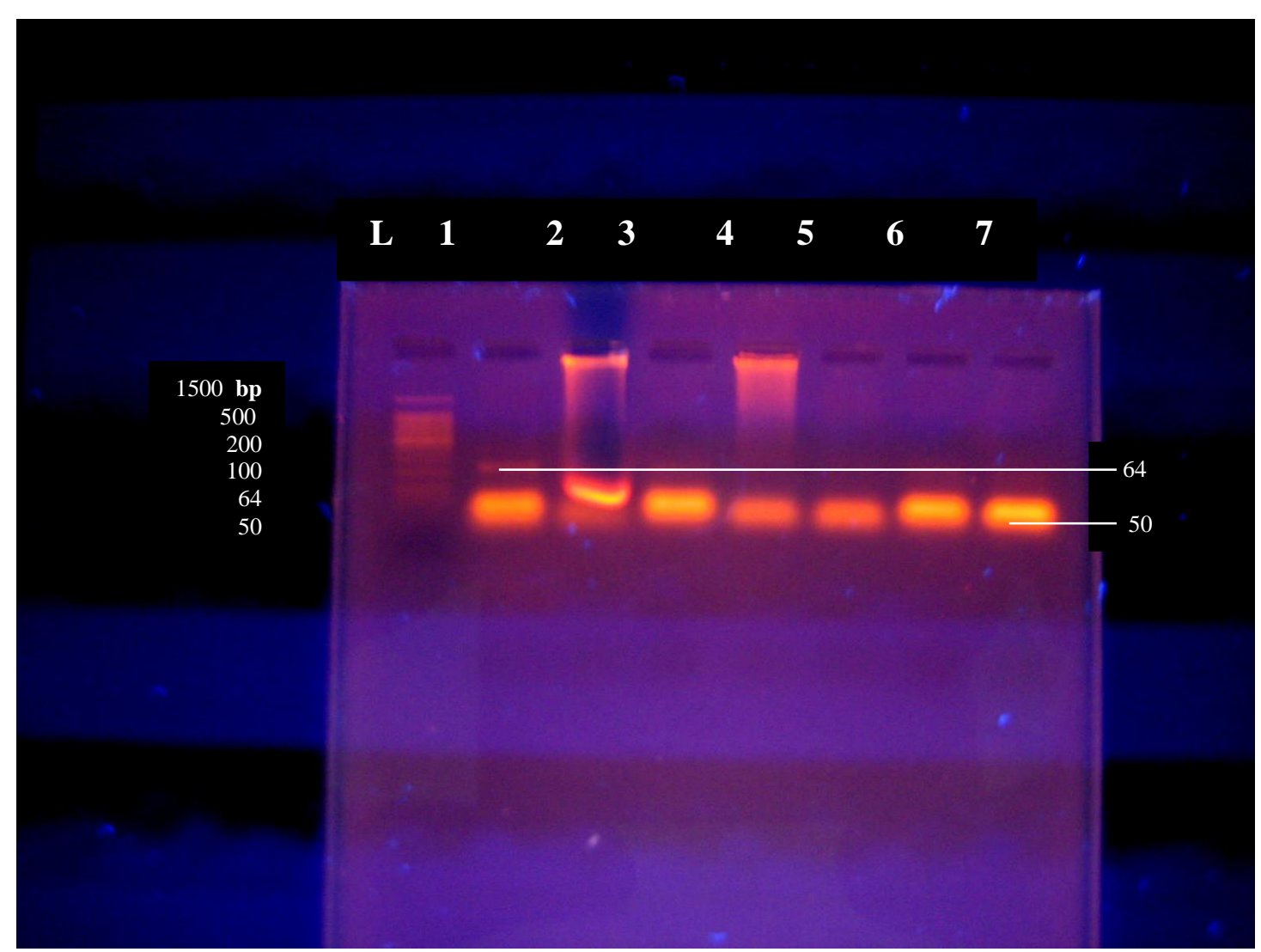

Fig .2. Hsp 92II restriction fragments of COMT alleles separated by agarose gel electrophoresis. Ladder. Lanes 3,6,7 show a homozygous low activity allele (Met/Met), Lanes 4,5 show a homozygous high activity allele ( Val/ Val ), and Lanes 1,2 the heterozygous pattern 


\section{DISCUSSION}

Analysis of genetic polymorphism in the COMT gene exhibit no association between the lowactivity alleles carriers (COMT Met) and breast cancer risk in young women. These results agreed with Millikan et al(8)they found no association between one or more copies of the low activity COMT allele and risk of breast cancer in a study that performed a population-based case-control including 654 invasive breast cancer cases and 642 controls of both pre-and postmenopausal women.

Thompson et al (9) found no association between the low - activity (COMT Met) allele and breast cancer among premenopausal individuals but, they found an inverse association in postmenopausal women.

Huang et al (4) found a significant association between the low activity of COMT Met/Met genotype and breast cancer risk in postmenopausal women compared with premenopausal women. While AL- Qurashi (7) found that the low activity of the COMT Met allele has 3-4 fold resulting in increased levels of circulating catechol estrogens and decreased formation of anti-tumorigenic, therefore, the COMT Met allele may increase the breast cancer risk because decrease the ability to methylate and detoxify catechol estrogen.

Reduced COMT activity may result in enhanced cell proliferation and increased formation of free radicals as a consequence of a possible accumulation of 4-HE and a decreased inhibition due to less synthesis of 2-ME2( 3 ).

Anna et al (10) referred that decreased COMT activity might increase the risk of breast cancer through an accumulation of(CE)which can cause oxidative to Quinines that react with DNA to form adduct this adduct can cause depuration leaving the purine site, which is the major type of genetic damage leading to mutation and genomic deletion during tumorigenesis.

Body Mass Index (BMI) may be an influence in breast cancer and this effect may be different depending on menopausal status, where the postmenopausal adipose women have been reported to be at higher risk of breast cancer, while a decreased risk has been observed in premenopausal women with high BMI (11). In this study, we haven't collected the information about BMI because it isn't reported in the hospital.

In conclusion, reduce (COMT Met) activity may in enhanced cell proliferation and increased the accumulation of (4-HE), and decreased the inhibition of angiogenesis due to loss synthesis of (2- ME). In this study, we did not show an increase in Angiogenesis of breast cancer risk associated with the low -activity of the COMT genotype.

\section{REFERENCES}

1. Laster, SC. \& Cotran ,R.S.( 2003). The breast: Robbins pathologic of medicine Basis, $7^{\text {th }} E D$. Chicago Uni. P.Sch of medicine, P:23(1093).

2. Zhu, B. T., and Conney, A.H. ( 1998) . Is 2Methoxy estradiol an endogenous estrogen metabolite that inhibits mammary carcinogenesis ? Cancer Res; 58: 2269 - 2277.

3. Bergman, MJ.\& Wingren, S. (2001). Catechol - O - Methyle Transferase (COMT)gene polymorphism and breast cancer risk in young women. British Jol of Cancer 85 (6):859 - 862.

4. Huang, CH; Chern, H.D; Chang, K.J; Hsu, S, M; and Shen, Ch.Y.(1999). Breast cancer risk associated with genotype polymorphism of the estrogen - metabolizing Genes CYP17, CYP1A1, and COMT : Amultigenic study on cancer susceptibility.Cancer Rech.Net.Taiwan University $.59: 4870-4875$. 
5. Sprudle, AB.; Hopper, JL.; Dite, GS.; and Chen, X.(2000). CYP17 promotor polymorphism and breast cancer in Australian women under age forty years. J.Nat Cancer Inst 92: 1674 -1681

6. Sam boork, J.; Fritsh, E.F, and Maniatis, T. (1989). Molecular cloning, a laboratory manual. $2^{\text {nd }}$ Ed. cold spring, harbor laboratory press. The USA. 7. AL- Qurashi, K.J.(2008) . The role of CYP1 B1 and COMT genes polymorphism as a risk factors of endometrial cancer in women. A thesis for Doctor of philosophy in biology, Bio-technology. College of Science. Basrah University.

8. Millikan,RC.; Pittman,GS. ; Duell,E. ; Newman, B. (1998). Catechol -O - Methyle Transferase and breast cancer risk. Carcinogenesis 19:1943-1947.
9. Thompson, PA.; Shields, PG.; Stone, A; Vena, JE.; Marchall, JR. (1998). Genetic polymorphism in catechol -o- methyle transferase, menopausal status and breast cancer risk. Cancer Res58:2107-2110.

10. Anna, H.W.; Tseng, C.; David, V.B.; and Mimi, C.V.(2003). Tea. Intake, COMT Genotype, and Breast cancer in Asian -American women. Amer. Asso. Cancer.Res (63): 7526-7529.

11. Van den Brandt, PA.; Spiegelman, D. ; Yaun, SS.; Besson, L .; Folsom, AR.; Fraser,G.(2000). Pooled analysis of prospective cohort studies on height, weight, and breast cancer risk. AM $J$ Epidemiol 15:514-527. 